\title{
Comissões de Saúde do Trabalhador da Educação em Serra-ES
}

\author{
Education Worker Health Commissions in Serra-ES
}

Jomar da Rocha Farias Zahn; Maria Elizabeth Barros de Barros; Cristiane Bremenkamp Cruz; Danuza de Oliveira Fonseca

Universidade Federal do Espírito Santo

\section{RESUMO:}

Este artigo traz discussões e fragmentos de uma trajetória de pesquisa-intervenção em Educação, utilizando o recurso de uma personagem, cujo nome é Celina, como dispositivo metodológico. Buscou-se acompanhar os processos em curso, relacionados à implementação da Comissão de Saúde do Trabalhador da Educação (Cosate) nas escolas públicas municipais na cidade de Serra, no Espírito Santo, de modo que ela funcione como um disparador de discussões em torno da forma como a educação se organiza e se atualiza. $\mathrm{O}$ estudo destaca a potência das redes para a contração de grupalidade no enfrentamento de políticas despotencializadoras dos coletivos de trabalho na educação. As Cosates, como espaços dialógicos de análise coletiva das práticas educacionais nas escolas, possibilitaram trocas e formação de redes afetivas de trabalho e saúde. $\mathrm{O}$ artigo apresenta, ao final, a potencialidade de coletivos de trabalho como modo de fazer frente à massificação e individualização que segmentariza e despotencializa no contemporâneo.

Palavras-chave: metodologia; trabalho; coletivo

\begin{abstract}
:
This article brings discussions and fragments of a research-intervention jorney in Education, making use of a character, whose name is Celina, as a methodological device. We sought to monitor the ongoing processes, regarding the implementation of the Education Worker's Health Commission (Cosate) in municipal public schools in the city of Serra, in Espírito Santo state, so that it functions as a trigger for debates around the way education is organized and updated. The study emphasises the power of networks for the contraction of the groupality in the confrontation of depotentializing policies of working groups in education. Cosates, as dialogic spaces for collective analysis of educational practices in schools, enabled exchanges and the formation of affective networks of labor and health. In the end, the article presents the potential of working collectives as a way to face the massification and individualization that segment and undermines in the contemporary.
\end{abstract}

Keywords: methodology; work; collective

DOI: 10.12957/mnemosine.2021.61852

Este artigo narra uma experiência que se atualizou entre 2017 e 2019 no decurso da pesquisa "Comissão de Saúde do Trabalhador de Serra/ES: sejamos realistas, tentemos o impossível", realizada no Programa de Pós-Graduação em Psicologia Institucional da 
Universidade Federal do Espírito Santo (UFES). Na pesquisa, foi construído um personagem conceitual, cujo nome é Celina, mulher, nordestina, professora em uma escola pública municipal na cidade de Serra, Espírito Santo. A partir de Celina, buscamos abordar a experiência de constituição de um fórum que envolveu diferentes atores da rede de ensino dessa cidade e se revelou um dispositivo para o fortalecimento e ampliação dos espaços coletivos de gestão do trabalho na referida rede. Indicamos, ainda, como efeito desse processo, a instituição da lei 4.513/18 ${ }^{1}$, que trata da constituição das Comissões de Saúde do Trabalhador em Educação (Cosates) como uma estratégia importante nessa direção ética e política, tendo como proposta contrair grupalidade.

\section{Movimento 1- do método da pesquisa}

Quando olhamos para o céu na sua concretude, vislumbramos movimentos, imagens em forma de objetos. A algumas dessas imagens atribuímos um sentido habitual e não nos surpreende, mas outras nos impactam e produzem sentimentos insuspeitos, bem como um curiosiar.

A azul cor do céu seria também a cor do mar? Ou o mar só reflete a cor que paira sobre ele? Ce, céu, linda, nasce Celina, uma personagem que vai crescendo, ganhando movimento no percurso Rio das Ostras x Vitória ${ }^{2}$. Afinal, o caminho é constituído de passos que se sucedem e não pode parar, mas há pausas, análises e outros movimentos.

Num desses momentos, criamos Celina para auxiliar a cartografar os processos em curso na rede de ensino do município da Serra/ES e trabalhar os tensionamentos entre conceitos e práticas, um instrumento importante durante a produção de dados na pesquisa, a fim de captar o dia a dia dos eventos vividos, as conversas, mas também o que acontecimentaliza nos caminhos da pesquisa.

Celina, nosso personagem conceitual (DELEUZE; GUATTARI, 1992), foi criada, portanto, para nos ajudar a compor as cenas que dão expressão à pesquisa. Um personagem que serve para transmitir eventos, de forma que seja possível uma ressonância com a pesquisa. Toda a narrativa foi construída em torno da experiência dessa personagem, que buscou expressar as apostas éticas, políticas e epistemológicas do processo investigativo. Celina é dotada de vida própria, atuando de forma a expressar essas diretrizes. A personagem conceitual, assim, não é a representante das pesquisadoras, mas, ao contrário, as pesquisadoras são apenas invólucros dessa personagem, uma espécie de 'heterônimo' das pesquisadoras e o nome das pesquisadoras são pseudônimos da 
personagem (DELEUZE; GUATTARI, 1992).

O diário de campo, uma escrita transversal, foi outra estratégia utilizada e sua leitura um modo que nos colocava a pensar no caminho investigativo que íamos construindo, a fim de operar nos eixos de duração e intensidade da pesquisa. A escrita transversal potencializa a superação de dois impasses: o de uma pura verticalidade e o de uma simples horizontalidade, uma vez que ela tende a se realizar quando uma comunicação máxima se efetua entre os diferentes níveis e, sobretudo, os diferentes sentidos que a escrita vai produzindo. Fala do que se faz, no que se faz e do que se faz, do que se fala. Fala do que nos escapa em meio às nossas ações, das invenções em meio às prescrições, fala das frestas que abrimos para oxigenar nosso poder de agir. Fala de (im)possibilidades, de saúde, de adoecimentos, de alegrias, de como habitamos os espaços do trabalho e como ele nos habita. Essa era a pista que essa modalidade de escrita nos facultava.

Ao lançar mão de uma personagem como percurso metodológico, tivemos o objetivo de captar as forças que emergem dos protagonistas das cenas que constituíram a história de um movimento de produção de grupalidade, de produção de coletivos que dão condições de emergência a uma política efetivamente pública.

Assim, entendemos que o diário transcende o registro. A escuta sensível das vozes dos trabalhadores/as/atores/as desse percurso e seu registro são fundamentais, pois elas caracterizam-se como elementos preciosos que atuam como potencializadores do processo de produção de dados e do mergulho numa teia que vamos tecendo num campo problemático, atentas a seus movimentos diários.

\section{Movimento 2 - do nascimento da personagem conceitual Celina}

Entre areia, barro, poeira, solo árido e ressecado, rachado pela seca, há crianças brincando na terra vermelha. É uma cidade pequena, com pouco mais de 146 mil habitantes. Há várias casas na vila chamada Bartolomeu, ponto de encontro das crianças do vilarejo para brincadeiras e, consequentemente, muito barulho, quintal com alguns pés de frutas. Nesse cenário, onde o sol forte castiga quase o ano todo, moram mulheres que têm muita força em seus olhos, corpos marcados pelas lutas travadas a cada dia de ida à roça, fazer o plantio, cultivo e colheita da cana-de-açúcar; mulheres que acariciam e incentivam o ruflar do ninho. Em uma dessas casas vive uma família formada por oito pessoas: pai, mãe e seus seis filhos; a mais nova é uma menina, Celina. Tertulina, mãe de Celina, é 'a maior das mulheres', 'a grande 'madre'... é uma sábia mulher. Possui estes 
atributos, pois está sempre atenta aos acontecimentos, sempre à sua espreita, e disposta à produção de novos saberes e conhecimentos; confiável; criativa e obstinada; ousada e precavida; abriga o tradicional e o original, inovadora.

Celina gosta de estar rodeada de gente, tem prazer em estar com todos, sejam de sua idade ou não. Ama deixar o tempo correr em rodas de conversa. Sua mãe diz que é meio intrometida, mas ela é mesmo curiosa. "Curiosidade é uma coceira que dá nas ideias" (ALVES, 2004: 22). Além disso, Celina sempre foi desbravadora. Desde a infância, observava tudo e perguntava o porquê disso, o porquê daquilo. Cresceu ouvindo folclore, músicas de cantigas de roda, como muitas das crianças daquele vilarejo. $\mathrm{O}$ curioso é que ao ouvir as canções cantadas pelos adultos e as histórias que seus pais contavam à noite ou pela manhã - depois do trabalho na roça -, lá ia ela recontar o que ouvira para os amigos.

Uma das brincadeiras favoritas das crianças era encenar as histórias que ouviam: o Saci, a mula sem cabeça, o homem do saco... Celina era a "diretora das peças/brincadeiras", dizendo onde cada um deveria ficar e que personagem ser, ou então uma atriz das histórias. E a imaginação dela e das outras crianças ia longe. Na escassez de brinquedos industrializados, tudo virava brinquedo.

Celina começa a experienciar a escola. A cada ano, novas descobertas: as letras, as palavras, as frases, os números, as continhas, as equações. Por assim dizer, vai se formando e formando os espaços escola/vida. Entre a dureza e a alegria que sustenta os modos de vida na roça, a escola com seu velho quadro-negro e os livros, as brincadeiras com os colegas, crescia a menina. Na escola, Celina era dedicada, mas brincava, fazia bagunça e comia a merenda duas vezes, se possível. Aprendeu as letras, que a levaram a livros cujas histórias a transportavam a outros mundos, outros saberes. Celina compôs com elas e compôs também.

A cada passo de Celina na escola, ela é tomada pela paixão de compartilhar. Compartilhar com os amigos vizinhos tudo que aprende. Quando decide pelo Magistério, talvez não soubesse que a "professora Celina" já estava sendo produzida, desde a infância e/ou adolescência. Vai saber! Na verdade, isso importa menos.

$* * *$

Professora Celina. Quem poderia imaginar? Muitos. Talvez até ela, em algum momento da sua vida. Alguns da vizinhança já diziam: "Essa menina tem jeito de 
professora!"’ Pronto, habemus Professora Celina.

E nesse arremesso da vida, agora a mulher cujo nome é Celina, sai para estudar, traçar um novo percurso, caminhos que uma garota de vila nem imaginava. É vida, tecida por encontros e desencontros, fazeres e desfazeres. Uma hora nosso corpo sente que somos um corpo formado de outros. Celina, corpo aberto, poroso, ora seguindo a cartilha pré-fabricada, ora se inventando. Segue para o inusitado. Celina vai dando passos, criando trilhas que a levam para outras paisagens. Celina sente o que pode o seu corpo-professora em um cenário no qual produzir brechas, criar rupturas, tensionar são necessários para não ser tão forma-atada às inúmeras regras e capturas de um mundo que nos busca formatar. Moça com sede de conhecer o mundo, que caminha para uma formação, mas formação além da lógica informacional, além do campo de saber escolarizado, formação para a própria vida nas dimensões variadas e diversas que a constitui (HECKERT; NEVES, 2007).

Estágio. É a hora pela qual Celina ansiava, ao contrário de algumas colegas, que descobriram que não queriam ser professoras, acreditavam que daria "muito trabalho". Outros sabiam que, apesar de esperarem melhor salário, um diploma nas mãos em um mundo tão competitivo ajudava. Celina observava aulas, ajudava a professora regente a preencher os muitos documentos que o Estado exigia: "Mas precisa de tanta burocracia?!"

Celina adorava as séries iniciais, sentia-se em casa. Em casa com as crianças, em casa nas atividades lúdicas, à vontade. Até se lembrou de quando era criança em seu vilarejo. Pois é. Agora é ir aprendendo a lidar com isso, com outros desafios. Celina estava se tornando professora. Seu sonho começava a ganhar concretude.

E, nesse caminhar, muitos flashbacks emergem nos pensamentos de Celina... Lá vem um pau de arara, e no seu balangar é perceptível que está lotado. Há trabalhadores de mãos calejadas pela enxada, outros com as mãos lisas sem ao menos ter trabalhado, talvez sonhadores, alguns com a pele ressecada pelo sol causticante, outros prospectando ganhar dinheiro, outros mudar de vida, outros apenas de carona, ou seja, o retorno de um dia laboral. Em cima do pau de arara há uma jovem, olhos amendoados cheios de expectativas. Durante o percurso, um buraco aqui, outro ali, uma descida, nova subida, costelinhas formadas pela chuva e o transporte trepida, o corpo todo chacoalha e vai se constituindo o caminho.

Ao passarem por uma curva, essa jovem mulher levanta sua cabeça para o céu, percebe que, para variar, hoje está sem nuvens, o sol escaldante sobre as cabeças novamente, dirige o olhar para o horizonte e vislumbra um solo árido, rachado e lembra: 
“É tempo de seca. Ah, meu sertão!” Na dança de seus pensamentos, sua trajetória vai se delineando.

Tempos difíceis aqueles que viveu, escassez de água e de comida e de muitas outras coisas necessárias para a sobrevivência das pessoas do vilarejo. Agora inicia seu jornadear a vida de retirante. Depois de tanta poeira e balangar, é hora de descer. Celina, a professora do Nordeste vai tentar a sorte numa outra cidade. Adeus, meu Nordeste, é o movimento da vida, vai ser gauche, ${ }^{3}$ agora será moradora da Região Sudeste.

$* * *$

Celina e a nova cidade onde residirá. Embarca no ônibus, sabendo que serão alguns dias, quem sabe de sol, quem sabe de chuva, quem sabe de engarrafamento, quem sabe de fome, frio e durezas. Naquele momento, nada importava para Celina. O pulsar do seu coração é "esperançar" outros ares, outra vida, com sua peixeira, que é o exercício de pensamento que corta e nos livra de várias estratégias de poder que tendem a nos capturar, nos fixar num modo sujeito.

O grande dia: o do desembarque, na rodoviária da Grande Vitória. A expectativa de novas oportunidades quase salta em seu peito, desafios por todos os lados, mas a certeza de que deseja desbravar novos caminhos.

Celina chega à cidade de Vitória, que faz parte da Grande Vitória. Abre sua pequena mala marrom, na tentativa de encontrar a garrafa de água. Passa a mão e percebe algumas roupas, um par de chinelos, um caderno de anotações, uma caneta sem tampa, duas escovas, uma para o cabelo e outra para os dentes, é o que trazia.

Ao desembarcar, Celina vê um livro de literatura da moça que desce na sua frente, lembra-se de um poema de Fernando Pessoa.

"Há doenças piores que as doenças Há dores que não doem nem na alma Mas que são dolorosas mais que as outras.

Há angústias sonhadas mais reais Que as que a vida nos traz, Há sensações Sentidas só com imaginá-las Que são mais nossas do que a própria vida. Há tanta cousa que, sem existir, Existe, existe demoradamente

E demoradamente é nossa e nós... Por sobre o verde turvo do amplo rio Os circunflexos brancos das gaivotas...

Por sobre a alma o adejar inútil Do que não foi, nem pôde ser e é tudo. 
("Há doenças piores que as doenças", Fernando Pessoa, 2012)

Seu telefone toca, é Deize, prima de Celina, moradora dessa cidade, avisando que já está chegando na rodoviária. As primas encontram-se, beijos, abraços, sorrisos e muito falatório. Celina respira fundo. Tem muito ar no peito, tem força de uma jovem iniciante na profissão.

\section{Movimento 3 - da emergência de uma professora}

Processo Seletivo Simplificado para professoras por Designação Temporária (DT). Celina prepara currículo, junta documentos, porque lera nos jornais sobre um processo seletivo da Prefeitura de Serra. Está animada com a possibilidade de se tornar professora, está animada a mostrar as maravilhas do seu sertão, gente beleza, povo guerreiro.

Sala 05. Turma A. Novo endereço de Celina. 87, número de matrícula. Os números organizam, identificam. Mundo estranho para Celina; de onde veio não era assim. Ela nem lembrava exatamente como era, só sabia que não era assim, parecia ser mais simples. De onde vinha, fazer amigos era algo mais simples: "Povo fechado. Sorrisos amarelos. Olhares assustados. Vai ver que é só no primeiro dia.”

Brigas por direitos. Cotas, greve de professoras, greve das funcionárias, paralisação de ônibus, "dia de luta contra isso, contra aquilo". Concursos. Processos seletivos. Passeatas. Greve. Polícia nas ruas. Concursos. Cortes no orçamento da educação... Passeatas. Silêncios. Polícia. Barulho. Sindicatos. Certificados. Protestos. Silêncio. Barulhos. Processos... assim caminha a cidade. Tudo muito, às vezes vácuos, perguntas sem respostas, e Celina tenta captar quais caos-processos que ela agora passa a (con)viver.

Diploma. Agora os movimentos são outros: ter um emprego, autonomia financeira. Currículo pronto. Processos seletivos. Contratos temporários. Concursos. É também hora de atualizar os ensinamentos da academia: "No estágio, parecia que a professora fazia diferente. Ou ela vem de uma formação pedagógica diferente da minha? "

Designação Temporária. Agora Celina vai ter o seu campo de trabalho. CelinaDT, professora de séries iniciais de uma escola pública. O corpo professora se prepara, se prepara até onde acha que pode. Ela sabe que tem muito a aprender. Já percebeu que são muitas as regras que compõem a instituição Escola. Enfim, de início, é vislumbrar o 
compartilhamento do que aprendera na faculdade. Além disso, já imagina que nas suas práticas seria difícil não trazer traços de onde veio, da Celina menina, da Celina que também foi aluna das séries iniciais, da guria contadora de histórias.

"Por que na escola tudo parece ser tão formatado, mensurado, calculado e burocratizado?"

Esse incômodo da nossa personagem pode parecer coisa de gente que está começando a carreira. De fato, os estranhamentos de quem entra no campo de trabalho, em particular o campo da educação (nosso destaque aqui), podem ser habituais. Mas como saber? Celina precisa garimpar esse campo, agora como educadora-aluna-do-mundo.

As muitas perguntas de Celina são perguntas de um corpo aberto, um corpo de escuta sensível. Sede de uma jovem profissional cheia de ideias, força física e que acredita que pode ajudar a mudar o mundo para um mundo mais solidário. "Quando uma pessoa vive de verdade, todos os outros também vivem. E todos nós, por meros momentos, voltamos a ser selvagens" (ESTÉS, 2007: 5). Quando uma criatura resolve se dedicar a viver do modo mais pleno possível, muitas outras que estiverem por perto se "deixarão contagiar".

$\mathrm{A} \mathrm{DT}^{4}$. Escola pública municipal. Colegas experientes-concursados.

"Só eu como DT?"

O espaço público parece um espaço privado. As professoras daquele turno, ao mesmo tempo em que não trocam ideias, parecem cada uma em casa no seu quarto, com seus televisores. O silêncio reina. As cadeiras da sala das professoras parecem ter nome; todos os dias as professoras sentam-se nas mesmas cadeiras. Olham para os relógios.

Sinal. Recreio. Pedagoga. Silêncio quebrado. Uma circular. Reclamações.

Que movimentos são esses que os olhos, ouvidos e fala de Celina nos trazem acerca da instituição escola?

"Circular $\mathrm{n}^{0}$ 10? As aulas começaram esta semana, eu fui contratada semana passada e já recebo a $10^{\mathrm{a}}$ circular? A pedagoga entrega, professoras reclamam. Quanto mais alto falam, menos eu as ouço. O povo não conversa aqui não?"

"Quanto menos puderem criar formas de trabalhar compatíveis com nossas expectativas e modificar o ambiente de trabalho de acordo com as nossas necessidades e desejos, maiores serão essas dificuldades" (BRITO; ATHAYDE; NEVES, 2003 : 52).

Analisam/conhecem o ambiente em que trabalham? "Relações hierarquizadas e censura de diálogos não podem fazer bem à saúde”, pensava Celina. 
Talvez Celina esteja comparando essa escola com o modelo de escola que ela imaginava e idealizava. Difícil. Difícil responder a tantas perguntas que iam surgindo a cada momento que transitava na escola. $E$ as questões não cessavam: será que tem que ser assim mesmo? Por que é assim? Qual o motivo de tantas circulares? Reclamações, SEDU, circulares... Celina já mexe o corpo como quem estivesse tentando achar a postura ideal, melhor, uma postura que a fizesse caber ali.

Celina ia se constituindo como uma mulher aberta ao mundo e incomodada com forças que pareciam querer capturar suas ideias e movimentos. Celina sente que escola, educação e ocupar espaços eram muito mais do que tudo que ela presenciava nos seus primeiros dias de professora (DELEUZE; GUATTARI, 1992).

Sala cheia. Um ventilador. Se por um lado o calor já fazia parte da vida de Celina, aquele cenário era outro. "Como suam os pobrezinhos..." "Professora, quantos anos você tem?" Celina sabe bem o que é ser criança curiosa, faladeira...

Celina tentava construir um outro caminho, um outro corpo, corpo da rapidez daquela cidade, de outro tipo de escassez. Escassez de espaços de conversa, de tempo de parar e tomar um café, não o engolir, escassez de ouvir o outro, escassez do improviso nas aulas quando não se tem material.

Que modo é esse dessa professora que vivencia e pratica o "curiosar" entrando no movimento da educação? Que práticas são essas de formação e burocratização que ela entende como pouco potentes? E as experiências de vida de suas amigas professoras? Como poderia tudo isso contribuir nas práticas educativas e no corpo-professora cujo "chefe" é o Governo?

Na escola, as instruções a serem seguidas pelo corpo pedagógico a incomodavam. Ela não as entendia - não eram práticas educativas que promoviam uma educação que aguçasse a curiosidade dos alunos, nem mesmo a imaginação. Celina, tocada pelo tarefismo escolar, o qual lhe era imposto, colocava tudo em questão.

Educação? Qual? O que queremos?

Como desenvolver um exercício autônomo das práticas educacionais se as políticas de governo estão mais para enquadrantes? Como pensar uma formação que possibilite saberes e relações sociais e efetivamente públicas? Como o corpo-professora vai se forjando formador e em formação junto com seus alunos, seus pares e o espaçoescola em meio a tudo isso?

Afinal, pensava Celina, por mais opressivo que seja o campo de trabalho, sempre é possível criar um espaço de liberdade, uma fresta que, mesmo que mínima, abra 
caminho para outros possíveis (GUATTARI; ROLNIK, 1996).

Alunos. Um aluno chega à escola de bermuda e uma camiseta vermelha com a foto do Che Guevara ${ }^{5}$ e não pode entrar, por conta da cor da roupa. A própria pedagoga não sabe onde estão as normas. Só diz: “Não pode, é uma regra. ” Lá, meninos não podem usar brincos, meninas não podem usar legging para não marcar a genitália.

Recreio. Surge um assunto entre um grupinho de meninas, alunas das séries finais. "Machista". Um "não" da pedagoga. Celina estranha. "Não é fácil tomar conta de tantas crianças. Ser administradora de escola é um desafio. Só uma pedagoga para trezentos alunos! Ela não deve ter muito tempo para atendê-los ou para pensar nas suas práticas. Deve falar muitos 'não' sem explicações".

Corpo pedagógico. "Sim." "Não." "São as regras." "Não tem jeito." “Assine a lista." "Atestado." “Atestado?!"

Celina ouve quase que diariamente tanto seus colegas quanto a coordenação pedagógica repetirem tais expressões. "Que profissionais cansados! Será que eu vou dizer as mesmas coisas?"

“Celina? É o seu nome, não é? Você é a novata. Olha, não se assuste com as nossas reuniões. Você está começando agora. Depois se acostuma. ”

Acostumar-se...

Será que a iniciante professora Celina, jovem e cheia de ideias, se acostumaria com falas que denotam tanto cansaço? O que pode um corpo ${ }^{6}$ inquieto? Na verdade, mais do que a sua jovialidade, as jovens, na vida real, geralmente têm uma impressionante sabedoria própria. Às vezes, porém, é também dominada pelo medo de seguir o que sua alma sabe. Ou ainda está num processo de aprendizado de enorme importância que, de repente, ou mesmo com o tempo, chegou a um impasse. O destaque a ser dado é seu modo de ver o mundo. Celina nasce e cresce em meio a inúmeras dificuldades, chega à Academia. A reinvenção sempre foi parte dela.

São as regras. "Esta informação, professora, só na SEDU."

Espaços de diálogo? Celina não via nem muito espaço, quanto mais diálogo... A impressão é que o importante é a ocorrência. ${ }^{7}$ Como formar cidadãos nesse espaço sem diálogo? Quem sempre tem razão? É a direção? Ou a Secretaria de Educação? Ou o que é definido para ela e os demais atores da escola? Que modos de fazer educação se atualiza quando não nos escutamos? Essas questões insistiam... Celina não cessava de se indagar.

Fatos e memórias. As memórias... Celina as deixava fluir. 
"Que valor tem um fato? O que resta dele além das sensações que nos deixa?" (RAMOS, 1982: 82).

Dias de sol, dias de chuva... Como fazer emergir Celina-mulher-adulta?

"Se Deus quiser quando eu voltar do mar, um peixe bom eu vou trazer" ${ }^{\text {. A música }}$ de Caymmi vai trazendo à memória o artista, porque ele capta o movimento do mundo $\mathrm{e}$ o expressa na obra de arte. Nesse sentido, o mais importante nos diálogos não é o elemento racional ou as contas, as argumentações, mas o sentido do que nos atravessa no momento desse encontro.

6:47. Parada solicitada. Seu telefone toca. Celina não consegue atender, pois o ônibus continua muito lotado. Mais um dia!

Passa pela banca da praça e vê no display de jornais:

“Concurso para professor efetivo no final no ano. Está aqui no jornal.” Emprego. Concorrer a uma vaga de emprego para professora efetiva anima Celina. "Já que faltam uns meses ainda, consigo acumular um tempinho de experiência e fazer alguns daqueles cursos de formação na SEDU. Quantas horas devem ter cada curso?"

Tempo que passa. Até que consiga se inscrever em um concurso e tentar ser aprovada, Celina tem muito caminho pela frente.

Habitar a cidade, seus espaços é o que convocava Celina, professora da educação infantil no turno vespertino há quase seis meses. No seu campo-escola de trabalho, ao formar crianças para darem seus primeiros passos na escola e lerem o mundo, também ajuda, em seu(s) campo(s) de atuação, os que por ela passam a exercitar o posicionar-se diante da vida. A prática educativa exige uma trabalhadora capaz de dar respostas para cada atitude, decisão, estratégias, novos olhares, pensar-se e construir outras bases, sempre novas às suas práticas educativas.

A escola é, geralmente, o lugar onde passamos o maior tempo de nossas vidas. É comum as pessoas pensarem que a escola é o único espaço de formação ${ }^{9}$. É usual pensar muito mais na formação do aluno e menos na formação do educador. Para muitos, a professora já vem formada, como se o(s) diploma(s) fosse(m) o suficiente para lidar com tantas histórias diferentes numa sala de aula - lidar com tantos colegas que carregam múltiplas marcas e histórias ao longo da profissão, sem falar do 'chefe' maior: a máquinagoverno.

Celina está sempre de olhos atentos aos movimentos da instituição escolar, o modo como as relações são atualizadas no cotidiano, a dinâmica de um sistema em que a burocracia se faz presente constantemente. Professoras trabalham também fora da sala de 
aula: elaboram murais, trabalhos a corrigir, atividades complementares a pensar, planejamentos diários e outras atividades. Muitas vezes, não é fácil pensar onde começa e termina o trabalho. É um cotidiano que envolve um emaranhado de tarefas: lançar notas, fazer correção de provas, planejamento de diários e de aulas, reuniões etc. Mas também sonhos...

Celina fecha a porta da sala de aula, põe os pés fora da escola; mas, ao chegar em sua casa, o trabalho não fica na escola; ele a acompanha.

Dever de casa da professora. Celina chega na escola pela manhã e tem as atividades que ao longo do dia vão se desdobrando. Quando encerra o dia, já se vê com as atividades do próximo. "Que dia exaustivo hoje. É a vida de professora que demanda muitos outros tempos. Tempo de hora-aula, tempo-espaço fora da escola.... Não nos contaram na faculdade que seria assim. Mas... tarefismos e burocracias à parte, não vou me deixar adoecer por isso. Vou criando linhas de vida, criando possíveis. "

Na escola, muitas vezes considera-se o trabalho das professoras reduzido à sala de aula e não se considera o restante do trabalho realizado, tampouco todo o esforço que as trabalhadoras da escola despendem para dar conta do que se espera e do que cada situação exige.

Escola rima com gaiola, mas não podem ser as mesmas coisas. Como é difícil um ofício no qual muitas vezes a profissional fica amarrada ao tecnicismo escolar.... Em apenas cinquenta minutos de aula, trinta alunos, fazer chamada, fazê-los se acalmarem, dar atenção àquele que faz perguntas e ter somente poucos minutos para dar o conteúdo pensado. Afinal, o trabalho na escola não é só o que ele parece ser (para quem está de fora, mas até mesmo para quem está dentro); ele não é só aquilo que segue um fluxo sem percalços e que é contabilizado em relatórios. As atividades desenvolvidas na escola são, muitas vezes, feitas silenciosamente, ninguém percebe o esforço excessivo praticado pela trabalhadora (BRITO; ATHAYDE; NEVES, 2003).

Celina encontra uma amiga no mercado.

"Ei Celina, e aí? Tá gostando?"

E ela pensa: “Como narrar para pessoas que não são da área de educação o que é ser professora, os baixos salários, o montante de trabalho, o lidar com crianças, a burocracia, o trabalho que não existe só no espaço da sala de aula? E se a pessoa que pergunta for da área, dependendo de como ela vê a profissão, posso corroborar algum pensamento desfavorável que ela possa ter. Enfim, a vida como ela é. Bem, a vida pode 
também ser outra. É movimento incessante. E falando em movimentos, por conta deles estou eu aqui."

"É. Ser professora tem seus desafios, demanda paciência, como todas as profisssões. Mas é isso, vamos caminhando. Estou aprendendo muito. ”

Solidão. "Quem entenderia a solidão de uma professora? Uma outra professora. Ora, se passamos por demandas parecidas, por que não nos unirmos? ”

Tarefa de casa da professora. São quatro horas da manhã. Entre os livros, artigos e rabiscos, Celina não consegue dormir, precisa escrever um projeto que vai desenvolver com seus alunos sobre História às avessas, mas as ideias não vêm, ela não consegue dormir... Põe uma música para relaxar, é Chico, o Buarque: Cálice ${ }^{10}$ Canta Celina: "Quero beber um pouco de Chico, relaxar e, quem sabe, retomar a escrita no dia seguinte."

Eu canto: Como é difícil acordar calado / Se na calada da noite eu me dano / Quero lançar um grito desumano / Que é uma maneira de ser escutado.

(Cálice, Chico Buarque e Gilberto Gil)

Ao mesmo tempo que ouvir uma canção a ajuda a pausar o pensamento que corria como um cronômetro, a canção a provoca no sentido de pensar a sua própria existência. Quantas vezes Celina é "calada" em seu trabalho, como formato-verticalidade da instituição em que ela trabalha?

Na educação, essa racionalidade se expressa nas práticas de gestão autoritárias, verticalizadas, hierarquizadas que não afirmam protagonismo de trabalhadoras que atuam no campo educacional, acarretando efeitos nas relações de trabalho na escola e, consequentemente, entre o trabalho e a saúde (CARDOSO; CÉSAR; BARROS, 2018).

Condições físicas de trabalho, modos de gerenciamento e gestão de trabalho, aspectos financeiros e relacionais falam de saúde e adoecimento na educação. Investigando esses fatores, destacam-se algumas fontes de tensão e adoecimento relacionadas com as condições de trabalho das profissionais da educação, em especial as professoras, como o ritmo intenso de trabalho, o número excessivo de alunos e a política de gestão da educação verticalizada e autoritária (GOTARDO et al., 2016).

O som abafado. Ao fazer um movimento para tranquilizar a mente, a canção a desperta. O que seria uma maneira de ser escutada? Como fazer surgir "essa palavra"? Essa palavra presa na garganta? Isso. Indo ao encontro das vozes. Ainda mais inquieta, volta à escrita. Retoma a empreitada.

Algumas coisas, Celina vai pensando.... É nas situações cotidianas da escola que os movimentos podem aparecer. Vem à mente um livro da adolescência, Aventuras de 
Alice no País das Maravilhas, de Lewis Carroll ${ }^{11}$, um relampejo a partir do qual evidentemente a primeira coisa a fazer seria um levantamento da região que iria atravessar. Alice também tinha um campo a atravessar. É muito parecido com estudar geografia, erguendo-se nas pontas dos pés na esperança de conseguir ver um pouco mais longe.

Celina pensa sobre o projeto que irá desenvolver na escola, batizado por ela de História às avessas. Precisa terminar a escrita deste projeto, que será desenvolvido com seus alunos. A proposta é que eles manuseiem os livros que só terão imagens, para depois criarem suas próprias versões das histórias e as contarem do jeito que quiserem, assentados em roda. Cada um terá a oportunidade de contar sua versão da história. Como proposta inicial, o primeiro livro de figuras será A flor do lado de lá, de Roger Mello. ${ }^{12}$

O projeto é uma nova experiência para Celina, que está empolgadíssima. Foi ligando para alguns colegas para ver se poderiam emprestar almofadas ou colchonetes para que, no momento da experimentação, a atmosfera ajudasse os/as alunos/as e colegas a serem contagiados pela proposta.

A atividade aqui é tomada como criação de mundos compartilhados. Ainda que o trabalho seja desenvolvido por um/a único/a trabalhador/a, a atividade pode ser entendida como encontro entre corpos. A trabalhadora constitui a sua atividade e é constituída por ela, corpo aberto às afecções do mundo. Trabalhar é ser capaz de estabelecer engajamentos em história coletiva. Um coletivo que possa compartilhar narrativas e análises sobre os processos de trabalho se fortalece com a sua própria renovação (SILVA; CÉSAR; BARROS, 2016).

Ela não está só. Uma professora informa a Celina que a professora de educação física possui tatames e que ela poderia conversar com a professora de Artes, a qual também poderia auxiliar com algumas misturas de cores das tintas, uma vez que estavam com poucas tintas. Assim, as crianças poderiam se pintar ou criar no próprio papel sua história. Celina começa a divagar em seus pensamentos...

A professora de Artes pergunta: "Celina, você não quer juntar as turmas?" Um projeto tão pequeno, sem grandes pretensões, agora está viabilizando outros agenciamentos, outros intercessores ${ }^{13}$ nesse processo. E como atrair mais colegas? O que as fariam motivadas a se envolverem nesse projeto?

O coletivo: como é dialogar com outros que têm outra experiência? Haveria coisas que precisariam ser pensadas quanto ao projeto e ao movimento em que seríamos 
inseridos. Como construir espaços de análise coletiva? Criar o coletivo para ultrapassar os modos individualizados que foram naturalizados. A liberdade é se indagar: Como estou fazendo? O coletivo é plano de coengendramento e de criação, indica um caminho peculiar e fecundo para a superação da dicotomia indivíduo e sociedade. É campo de forças que dá nascimento a outras formas, outras realidades, outros mundos (ESCÓSSIA; KASTRUP, 2005).

Como se constrói um coletivo na escola?

Dois é bem melhor, "eu e $+1 \ldots$ "..14; mais pessoas pensando juntas é melhor ainda. Celina alegra-se em ver a movimentação. "Demorou! Mas é possível. Que legal! ”É notório que as relações contemporâneas têm sido marcadas pela proliferação de comportamentos individualizados. Paradoxalmente, no campo da educação, vão sendo demarcadas necessidades de trabalhos colaborativos, em equipe, em rede, trabalhos solidários num processo de comunicação transversalizado, ou seja, em diferentes e múltiplas direções, sem direção hierarquizada.

Celina fala: "O que nos impede de nos colocarmos em conversa? Um põe uma ideia, outro coloca outra, que pode se conectar à outra ideia, e assim vamos construindo um novo saber para o trabalho que não estava posto?" O convite de Celina: criar impensáveis percursos, impulsionar movimentos diversos, de forma coletiva.

A ideia do projeto vem de antigos escritos de Celina. Um caderno da faculdade no qual ela rabiscava possíveis projetos para algumas de suas disciplinas. Sempre gostou de escrever, fazia registros acerca do que se passava com ela. A escrita é um caso de devir, sempre inacabado, sempre em vias de se fazer e que extravasa qualquer matéria vivível ou vivida. É um processo, ou seja, uma passagem de Vida que atravessa o vivível e o vivido. A escrita deve ser vista como um corpo entre outros corpos e não como um plano paralelo que os espelharia. Produz real e age diretamente nele, escrita ao rés do real... para falar desse corpo do escrito, que é tão real e interventivo na realidade quanto os demais corpos ou objetos do mundo, Celina pensava... É nesse sentido que talvez possa falar de uma poética, na contramão, metafórica ou representacional. Não se trata de representar um sujeito na escrita, mas de fazer da escrita o drama de uma voz que se faz na própria superfície das palavras, em meio a muitos cruzamentos que passam por elas, entre elas.

De um colega que a ajudaria inicialmente, agora já são quatro. O professor de Educação Física, a de Artes, o de Matemática e a de Português se ofereceram para ajudar na logística no dia da apresentação, e as turmas também iriam se juntar.

Proposta entregue à pedagoga: "Que dia vocês estão pensando em fazer isso?" 
"No dia da família. Já está no calendário mesmo. [...]"

"Não temos dinheiro."

"E se enviássemos uma carta aos pais para trazerem algum lanche? São quatro turmas envolvidas e os colegas de Artes e de Educação Física ensaiarão uma música com as crianças. Bom, vai sujar um pouquinho, mas é conversar com as meninas da limpeza e faremos um esforço coletivo de higienização do espaço, não será fora do horário delas. "

"Ufa! Como contagiar um colega de trabalho? Melhor, como contagiar vários colegas de trabalho?"

Contágio como movimento para colaborar na construção de um corpo coletivo mais aberto e vital, aquele sem narrativa linear, mas que os agrupamentos circunstanciais e a proposição de mente e corpo façam vir à tona afetos, produzir contágios a partir do processo movente.

Contagiar é o processo de propagação de crenças e desejos em um campo de abertura $e$ de afinidades construídas em relação, é muito mais que convencer. Podemos convencer trabalhadores a participar de um projeto? Mas podemos partilhar com eles sonhos e desejos, de tal forma que esses trabalhadores também abracem o movimento e produzam estratégias para continuar participando, se disponham a conversar sobre sua experiência em diversos espaços com o fim de também produzir deslocamento em outros trabalhadores da educação. É muito mais que convencer. Contagiar, imitação, compreende uma abertura ao plano comum, no qual há a intensificação e o fortalecimento das linhas que unem o coletivo heterogêneo. O processo de contágio diz do engendramento de uma relação, da efetivação da intervenção na qual não há efeitos prontos e conhecidos (BRITO, 2018: 49).

\section{Movimento 4 - Celina encontra as COSATES}

Essa inquietação levou Celina para a universidade federal da cidade. Será que posso encontrar lá alguma coisa que me ajude a fortalecer essa grupalidade na escola? Uma consulta à biblioteca, quem sabe?

O tempo estava cinza, parecia que ia chover, mas Celina, mesmo assim, decide ir à Biblioteca da Universidade. Ao chegar no campus, avista um prédio cinza, com janelões cheios de grades, e se inquieta: por que os livros vivem presos, como que engaiolados? Tantos saberes detidos, proibidos de voarem, devaneia Celina enquanto caminha vislumbrando a grama, os micos e pássaros, até a entrada principal.

Dirige-se até o balcão de atendimento e pergunta: “Onde posso encontrar a bibliotecária"? É informada que deveria subir um lance de escada e lá encontraria a bibliotecária de plantão cujo nome era Joanna.

Celina sobe ligeiramente a escadaria e procura por Joanna, que a recebe com um 
olhar simpático e atento.

Juntas, vão ao computador da biblioteca e Joanna explica como usar a tecnologia para pesquisa.

Joanna lhe diz: "Acho que você pode encontrar alguma coisa que te interessa naquela estante no primeiro andar à esquerda. "

Depois de algumas olhadas na estante, depara-se com um documento cujo título é Caderno de Formação: Saúde no Trabalho e Educação e que lhe parece interessante. O material narra uma experiência que teve início em 2012, quando um Programa de Formação e Investigação em Saúde do Trabalhador (PFIST), vinculado ao Núcleo de Estudos em Subjetividade e Políticas (Nepesp) do departamento de Psicologia da Universidade Federal do Espírito Santo (Ufes), realizou um mapeamento das condições de trabalho e saúde das professoras do ensino fundamental da rede pública da Serra/ES.

As docentes foram selecionadas a partir de uma amostragem estatística aleatória, com base nos dados fornecidos pela Secretaria de Educação da Serra (SEDU) em 2011, referente ao quantitativo de 2.566 professores da rede de ensino, efetivos ou contratados. A pesquisa foi distribuída pelas seis Regiões Geopedagógicas ${ }^{15}$ do município, envolvendo 50 professores por região, totalizando 300 professores participantes do estudo.

Celina suspirou. Ufa... e olhando na mesma prateleira, encontra outro material. Era um artigo sobre a mesma temática; começa a folhear e, na sua leitura, depara-se com a escrita:

As pesquisadoras do PFIST relatam que um mapeamento foi realizado por meio da aplicação de um Questionário para inquérito epidemiológico com levantamento de dados relacionados às variáveis sociodemográficas, de percepção sobre saúde e trabalho e sobre situações relacionadas à saúde mental baseado no Self Report Questionnaire (SRQ 20). De modo geral, esse levantamento apontou altos índices de transtornos cardiovasculares e gastrointestinais entre os docentes que, articulados ao stress, tensão e ritmos intensos nos levaram a compreender também os problemas osteoarticulares, auditivos e vocais que vêm marcando os modos de organização e gestão da Educação e do ofício de professor (LUCIANO et. al, 2012).

Os dados desse mapeamento indicaram que o processo de doença não é uma questão pessoal, individual, já que os índices mais expressivos quanto à fonte de tensão, adoecimento e cansaço no trabalho apontaram exatamente os processos de trabalho: salas superlotadas, sensação de isolamento, carga horária intensa, individualização, política de gestão autoritária, ruídos excessivos etc.

Diante deste quadro, as pesquisadoras definiram uma estratégia para intervir nas condições e modos de organização do trabalho e investir em práticas cogestivas e 
coletivizadas como estratégia na direção da produção de saúde. Assim, nasceu o PFIST: uma aposta na produção de uma política pública via implantação das Comissões de Saúde do Trabalhador (COSAT).

A partir dessa leitura, algumas coisas começam a fazer outras conexões com o que Celina vinha arquitetando. Prossegue lendo o texto.

Para elaborar uma política pública de saúde para a Educação de Serra, em 2012 foi constituído um fórum, o qual foi denominado Fórum de Discussão das Comissões de Saúde do Trabalhador da Educação (Fórum Cosate). Diversas pessoas, grupos e agentes de órgãos municipais (CEREST, Medicina do Trabalho, Perícia Médica, Escolas, Ministério Público, Sindicato Estadual dos Professores (SINDIUPES), Associação de Pais ASSOPAES/Serra), dentre outros, compuseram o Fórum Cosate, que se estendeu até o ano de 2018 com periodicidade variável, quinzenal ou mensal, neste período.

Os encontros do Fórum Cosate aconteciam predominantemente no Centro de Formação de Professores, órgão da Secretaria de Educação Municipal de Serra/ES e, às vezes, em escolas da rede, tendo como uma das suas principais metas discutir sobre as condições de saúde e trabalho com os trabalhadores da Educação e elaborar uma lei Cosate para a Educação de Serra.

Empolgada com a leitura, Celina compreende como se deu a constituição do fórum e prossegue lendo sem perceber as horas passarem.

A aposta não era unicamente criar uma lei de forma burocrática, como acontece em muitas proposições legais desvinculadas dos debates para suas constituições, mas sim afirmar a elaboração de uma Lei-Cosate como um dispositivo capaz de disparar produção subjetiva em favor da saúde. A inclusão das trabalhadoras-educadoras na produção da lei tornou o fórum um espaço de produção de saúde e a elaboração da Lei Cosate um dispositivo dinâmico e pulsante que alinhavava, encontro a encontro, um movimento de construção de uma política de saúde na educação para o município de Serra. A proposição da Lei Cosate, feita pelo Fórum Cosate, perseguiu outras formas de constituição e movimento que estivessem pautadas na coconstrução com as trabalhadoras da educação.

Celina respira, suspira e sussurra que a Cosate foi feita para/com as trabalhadoras da educação.

Assim, os autores destacam, no caderno de formação, que, ao pensar o projeto de lei que institui as Cosates como ferramenta para construir e contagiar, a lei se torna um dispositivo. A lei que abre... A ideia, que só foi possível ser elaborada depois de vários 
encontros do grupo do PFIST, era usar os modos de funcionamento que achatam o tempo e o diálogo para possibilitar o inverso; um impulso no jogo de forças que movimentam esse cenário, mas ela em si não resume ou se constitui como finalidade de política pública - ela possibilita a participação das professoras na sua constituição, o que define uma política pública: participação coletiva com todos os embates e tensionamentos que um processo de formação de um 'grupo sujeito' ${ }^{16}$ exige. A lei, entretanto, alerta o documento, não é suficiente, não resolve por si; é necessário um processo de contágio que tome as pessoas, de forma que possam apostar e dar credibilidade a esse processo para a produção de saúde nas escolas. Por outro lado, é produção de abertura quando ela se converte/constitui como uso dos efeitos de lutas (BRITO, 2018).

Joanna aproxima-se de Celina e pergunta se conseguiu encontrar o que procurava e, então, explica que está em estágio probatório na biblioteca e, anteriormente, trabalhou como professora de Serra e participou do movimento da Cosate.

E começam a conversar.

Joanna diz: "Durante esse movimento da Cosate, que se deu na educação pública no município de Serra, a experiência de debater, propor e aprovar uma lei de implementação de Comissões de Saúde do Trabalhador da Educação foi muito rica. O objetivo não era tornar as Cosates um modelo a ser implantado, tampouco apostar que fosse a única forma de organizar espaços cogestivos nas escolas". E, então, pergunta: “A partir dessa rápida olhada, você percebeu esse movimento das Cosates como um dispositivo para experimentar e ampliar a experiência cogestiva? Para mim ficou bem nítido que é preciso apostar na criação de muitos dispositivos que possam ser inventados a depender dos contextos singulares e dos trabalhadores envolvidos em seus territórios específicos de atuação. O objetivo era dar visibilidade a um trabalho que realizamos cotidianamente e não está prescrito nos regulamentos das escolas".

Celina sorri e responde: "Sim, o que se destaca, nessa primeira olhada, é que a proposta da Cosate está para além de uma lei, ou de uma experiência acadêmica, acho isso muito bom!"

Joanna prossegue: “A aposta é de nos orientarmos por uma análise que possa acompanhar os processos em curso no trabalho docente. A força dos debates produzidos no Fórum Cosate nos indica a potência desse processo para uma vida mais potente e criativa, nos faz pensar que é sempre possível criar modos de viver menos limitadores."

Essa é, então, a proposta das Cosates, pensa Celina: criar meios para a efetivação de uma análise dos processos de trabalho e o compartilhamento de estratégias de ação 
como formas genuínas de fazer frente à massificação, sujeição e despotencialização da vida coletiva. A produção e análise, a experiência permanente de coletivização se fez possível e se operou no transcurso de ações vinculadas às Comissões de Saúde do Trabalhador de Serra-ES entre 2017 e 2019.

Joanna sugere que Celina procure frequentar os Fóruns Cosates para compreender melhor a proposta.

Celina parecia ter encontrado algumas pistas.... Foi se aproximar do fórum e aprender no processo cogestivo como constituir/criar uma política pública na educação.

\section{Referências}

ALVES, Rubens. Desejo de ensinar e a arte de aprender. 2. ed. Campinas: Fundação Educar, 2004.

BRITO, Hervacy. Formação e comunicação imidiática no movimento desejante Fórum Cosate, 2018. Tese (doutorado em Educação) - Universidade Federal do Espírito Santo, Centro de Educação, Vitória, 2018.

BRITO, Jussara.; ATHAYDE, Milton.; NEVES, Mary. Caderno de textos: programa de formação em saúde, gênero e trabalho nas escolas. João Pessoa: Editora Universitária /UFPB, 2003.

CARDOSO, Jaddh Y. M.; CÉSAR, Janaína M.; BARROS, Maria E. B. Conversas preliminares. In: BONALDI, Cristiana. M.; CRUZ, Cristiane B.; CORREIA JUNIOR, José A. Caderno de Formação: Saúde no Trabalho em Educação. Vitória: Fundacentro, 2017. p. 14-30.

CARROL, Lewis. Aventuras de Alice no país das maravilhas: através do Espelho e o que Alice encontrou por lá, Rio de Janeiro: Zahar, 2009.

CAYMMY, Dorival. Minha jangada vai sair para o mar. (música) 1972

DELEUZE, Gilles. GUATTARI, Félix. O que é a filosofia? Trad. Bento Prado Jr. e Alberto Alonso Muñoz. Rio de Janeiro: Editora 34, 1992.

ESCÓSSIA, Liliana; KASTRUP, Virginia. O conceito de coletivo como superação da dicotomia indivíduo sociedade. Psicologia em Estudo, Maringá, v. 10, n. 2, p. 295 304, maio/ago. 2005.

ESTÉS, Clarissa P. A ciranda das mulheres sábias, ser jovem enquanto velha, velha enquanto jovem. 1. ed. São Paulo: Rocco, 2007.

GOTARDO, Suzana. M. et al. O processo de formação de Comissões de Saúde do Trabalhador da Educação: experiência e política. Revista de Ciências Humanas, Florianópolis, v. 50, n. 2, p. 334-353, jul./dez. 2016.

GUATTARI, Félix; ROLNIK, Suely. Cartografias do desejo. Petrópolis: Vozes, 1986.

GUATTARI, Félix. Revolução molecular: pulsações políticas do desejo. São Paulo: Brasiliense, 1987. 
HECKERT, Ana L. Claudia.; NEVES, C. Modos de formar e modos de intervir: quando a formação se faz potência de produção de coletivo. In: PINHEIRO, Roseni et at. (orgs.). Trabalho em equipe sob o eixo da integralidade: valores, saberes e práticas. Rio de Janeiro: IMS/Uerj, Cepesc, Abrasco, 2007. p. 145-160.

LUCIANO, Luzimar S. et al. Mapeamento das condições de saúde e trabalho dos professores do município da Serra/ES. COLÓQUIO INTERNACIONAL DE PSICOSSOCIOLOGIA DO TRABALHO, 1., 2012, Belo Horizonte. Anais... Belo Horizonte: UFMG, 2012.p.17

MELLO, Roger. A flor do lado de lá. Rio de Janeiro: Global, 2001.

RAMOS, Graciliano. Cartas. Rio de Janeiro: Record, 1982.

SILVA, Fábio. H.; CÉSAR, Janaína M; BARROS, Maria E. B. de. Saúde e trabalho em educação: desafio do pesquisar. Vitória: EDUFES, 2016.

Jomar da Rocha F. Zahn

Universidade Federal do Espírito Santo

E-mail: jomarzahn@gmail.com

Maria Elizabeth B. de Barros

Universidade Federal do Espírito Santo

E-mail: betebarros@uol.com

Cristiane Bremenkamp Cruz Universidade Federal do Espírito Santo

E-mail: crisbremenk@gmail.com

Danuza de Oliveira Fonseca

Universidade Federal do Espírito Santo

E-mail: danfosek19@gmail.com

\footnotetext{
${ }^{1}$ Decreto de Lei N. 4513.05 de maio de 2016 da Prefeitura de Serra/ES que criou a Comissão de Saúde do Trabalhador da Educação (COSATE) como um serviço público do referido município, assim como o Conselho das Comissões de Saúde do Trabalhador da Educação (CONCOSATE).

${ }^{2}$ A autora principal do artigo reside em Rio das Ostras e realizava seu mestrado no Programa de Psicologia Institucional da UFES/Vitória.

${ }^{3}$ Gauche refere-se ao Poema de sete faces, de Carlos Drummond de Andrade (1930).

${ }^{4}$ DT é um termo que é utilizado para Designação Temporária, um tipo de contrato de trabalho por tempo determinado.

${ }^{5}$ Ernesto Guevara (Rosário, 14 de junho de 1928 - La Higuera, 9 de outubro de 1967), mais conhecido como "Che" Guevara, foi um revolucionário marxista, médico, autor, guerrilheiro, diplomata e teórico militar argentino.

${ }^{6}$ Ao usarmos "O que pode um corpo inquieto?", nos remetemos a Espinoza em um de seus textos: "O que pode um corpo?” O que pode o corpo? Corpografias de resistência, Ética. São Paulo: Abril Cultural, 1973. (Coleção Os pensadores, v. XVII).

${ }^{7}$ Ocorrência é um documento utilizado quando a(o) aluna(o) comete um ato infracional ou quando comete três atos indisciplinares, daí assina uma ocorrência. $\mathrm{O}$ aluno deverá estar acompanhado pelos pais ou responsáveis para a assinatura.
} 
${ }^{8}$ A letra cantada por Celina é de Dorival Caymmi. Chama-se "Suíte do pescador" e está no álbum Caymmi e o Mar.

${ }^{9}$ Usamos aqui o sentido habitual de formação, aquela que se opera por processos de escolarização.

${ }^{10}$ Cálice é uma canção escrita e originalmente interpretada pelos compositores brasileiros Chico Buarque e Gilberto Gil em 1973, mas lançada somente em 1978. Censurada pela ditadura militar, a canção foi liberada cinco anos depois e apareceu pela primeira vez no álbum Chico Buarque, tendo Milton Nascimento e MPB4 cantando com Chico e, em seguida, no álbum Álibi, de Maria Bethânia.

${ }^{11}$ Charles Lutwidge Dodgson, mais conhecido pelo seu pseudônimo Lewis Carroll (Daresbury, 27 de janeiro de 1832 - Guildford, 14 de janeiro de 1898), foi um romancista, contista, fabulista, poeta, desenhista, fotógrafo, matemático e reverendo anglicano britânico. Lecionava matemática no Christ College, em Oxford. É autor do clássico livro Alice no País das Maravilhas, além de outros poemas escritos em estilo nonsense ao longo de sua carreira literária, que são considerados políticos, em função das fusões e da disposição espacial das palavras, como precursores da poesia de vanguarda.

${ }^{12}$ Roger Mello é um escritor e ilustrador brasileiro. Nasceu em Brasília, em 1965. Vencedor do Prêmio Internacional Hans Christian Andersen 2014, na Categoria Ilustrador. O prêmio é concedido pelo International Board on Books for Young People (IBBY), considerado o Prêmio Nobel da Literatura Infantil e Juvenil. A patrona do prêmio é a Rainha Margrethe II, da Dinamarca.

${ }^{13}$ Intercessores podem ser pessoas, coisas, plantas; é o exercício do pensamento a possibilidade de novas formas de expressar o pensar. É um companheirismo na escrita e na leitura.

${ }^{14}$ Nome de um documentário de Eliane Brum, com o título n+1. Disponível no canal youtube.

${ }^{15}$ O município de Serra/ES está dividido em seis regiões geopedagógicas, caracterizadas de acordo com a localização. São elas: José de Anchieta, Carapina I, Carapina II, Serrana, Civit e Litoral.

${ }^{16}$ Grupo sujeito é uma formulação de Felix Guattari para se referir a um grupo cuja transversalidade é ampliada, conectado a elementos complexos, históricos, sociais, político-econômicos, estéticos. Um grupo que cada vez mais, toma posse de sua própria voz. A esse grupo Guattari (1987) definiu como sendo "grupo sujeito", em contraposição ao "grupo sujeitado", cujas leis de funcionamento the vinham de instâncias exteriores. 